\title{
Size control of self-assembled quantum wires for emission wavelength engineering
}

\author{
L. González ${ }^{1}$, Y. González ${ }^{1}$, D. Granados ${ }^{1}$, J. M. García ${ }^{1}$, D. Fuster ${ }^{2}$ and J.Martínez- \\ Pastor $^{2}$ \\ ${ }^{1}$ Instituto de Microelectrónica de Madrid (CNM-CSIC), C/ Isaac Newton 8 (PTM). \\ 28760-Tres Cantos (Madrid). Spain. \\ Phone: 34-91-8060700, Fax: 34. 91-8060701 \\ ${ }^{2}$ Instituto de Ciencia de los Materiales, Universidad de Valencia, P.O. Box 2085, 46071 Valencia, Spain. \\ Phone:34-96-3864041, Fax: 34-96-3983021
}

\section{Summary}

It is now well established (1-5) that nanowires formation along [1 $\overline{1} 0]$ takes place when an InAs thin layer (about 2.7 monolayers, ML) is grown by MBE on InP (001) substrate.

Strain relaxation is the driving force for the unidirectional observed surface roughening due to the asymmetric accumulated stress induced during $\mathrm{MBE}$ growth of a latticemismatch III-V/III-V' heteroepitaxial system (6).

In the case of InAs/InP(001) system, the nanowires covered with an InP cap layer produce photoluminiscence $(\mathrm{PL})$ emission at $\lambda \approx 1.5 \mu \mathrm{m}$ at room temperature $(3,7)$. However it should be desirable to exactly tune the emission wavelength to the optimum for communication devices $(\lambda=1.55 \mu \mathrm{m})$ as well as to any other wavelength under design.

One possible way to tune emission wavelength is to actuate on carrier confinement by using ternary alloys instead of InAs to change both lattice-mismatch (with influence on the size of the nanowires) and composition (introducing changes in band gap of the materials in the nanowires).

In this work we have grown by $\mathrm{MBE}$ samples consisting of $\operatorname{In}_{1-\mathrm{x}} \mathrm{Ga}_{\mathrm{x}} \mathrm{As}$ and $\mathrm{In}_{1-\mathrm{x}} \mathrm{Al} \mathrm{l}_{\mathrm{x}} \mathrm{As}$ $(0<x<0.85)$ with different thickness, at a growth rate $r_{g}=0.1 \mathrm{ML} / \mathrm{s}$ and substrate temperarure $\mathrm{T}_{\mathrm{s}}=490^{\circ} \mathrm{C}$.

Measurements of surface topography made by atomic force microscopy (AFM) show that the period of the wires change from $17 \mathrm{~nm}$ to $45 \mathrm{~nm}$ for a change in lattice-mismatch from $3.2 \%$ to $2.2 \%$.

Results on PL emission wavelength range obtained in similar samples but adding an InP capping layer will be shown.

\section{References}

1) J. Brault, M. Gendry, G. Grenet and G. Hollinger, Appl. Phys. Lett. 73, 2932 (1998)

2) H. Li, J. Wu, Z. Wang, and T. Daniels-Race, Appl. Phys. Lett. 75, 1173 (1999)

3) L. González, J. M. García, R. García, F. Briones, J. Martínez-Pastor, and C. Ballesteros, Appl. Phys. Lett. 76, 1104 (2000).

4) C. Walter, W. Hoerstel, H. Niehus, J. Erxmeyer and W. T. Masselink, J. Cryst. Growth 209, 572 (2000).

5) H. R. Gutiérrez, M. A. Cotta and M. M. G. De Carvalho, Appl. Phys. Lett. 79, 3854 (2001).

6) J. M. García, L. González, M. U. González, J. P. Silveira, Y. González and F. Briones, J. Cryst. Growth 227-228, 975 (2001)

7) B. Alén, J. Martínez-Pastor, A. García-Cristobal, L. González and J. M. García, Appl. Phys. Lett. 78, 4025 (2001) 

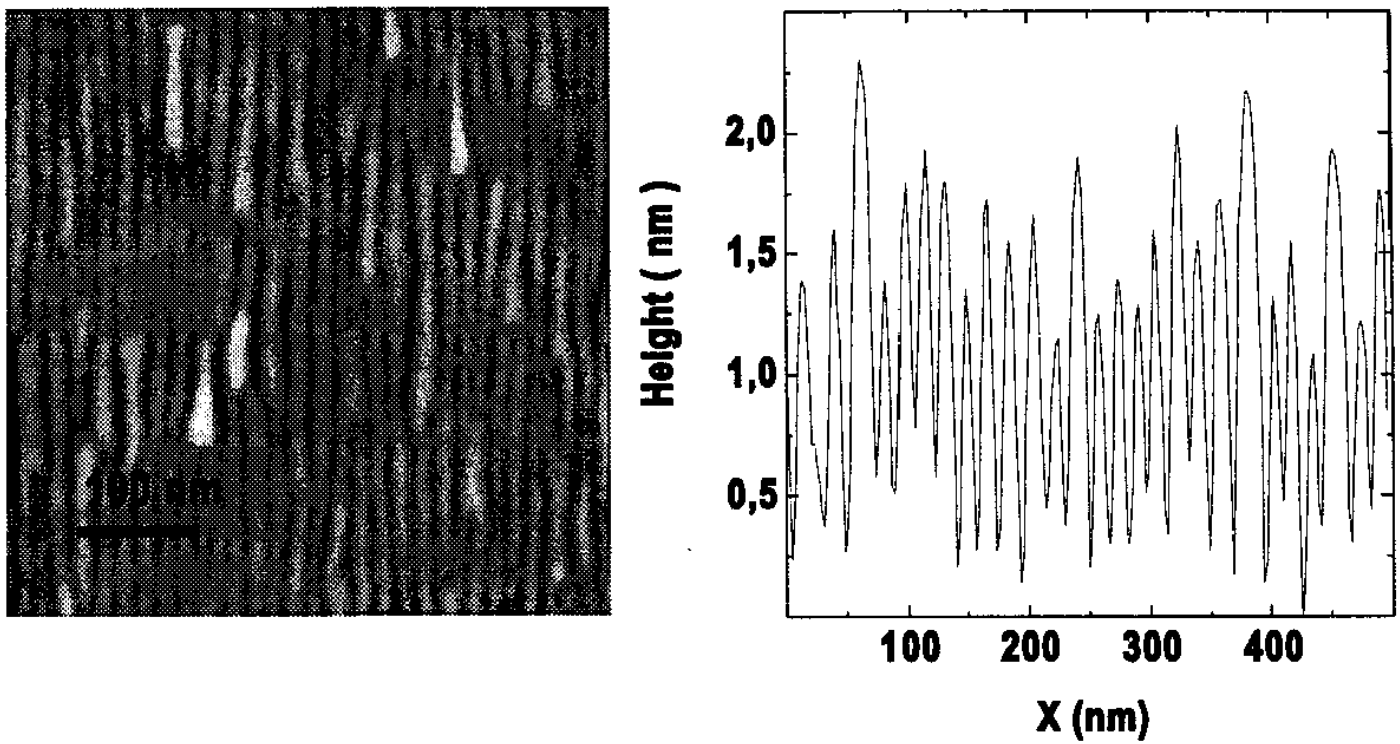

Fig. 1 : Atomic Force Microscopy (AFM) view of nanowires formed along [11i0] by growth of 2.7 monolayers of $\operatorname{InAs}$ on $\operatorname{InP}(001)$. Profile along [110] shows a wire pitch period of $17 \mathrm{~nm}$ and average height $\approx 1.7 \mathrm{~nm}$.
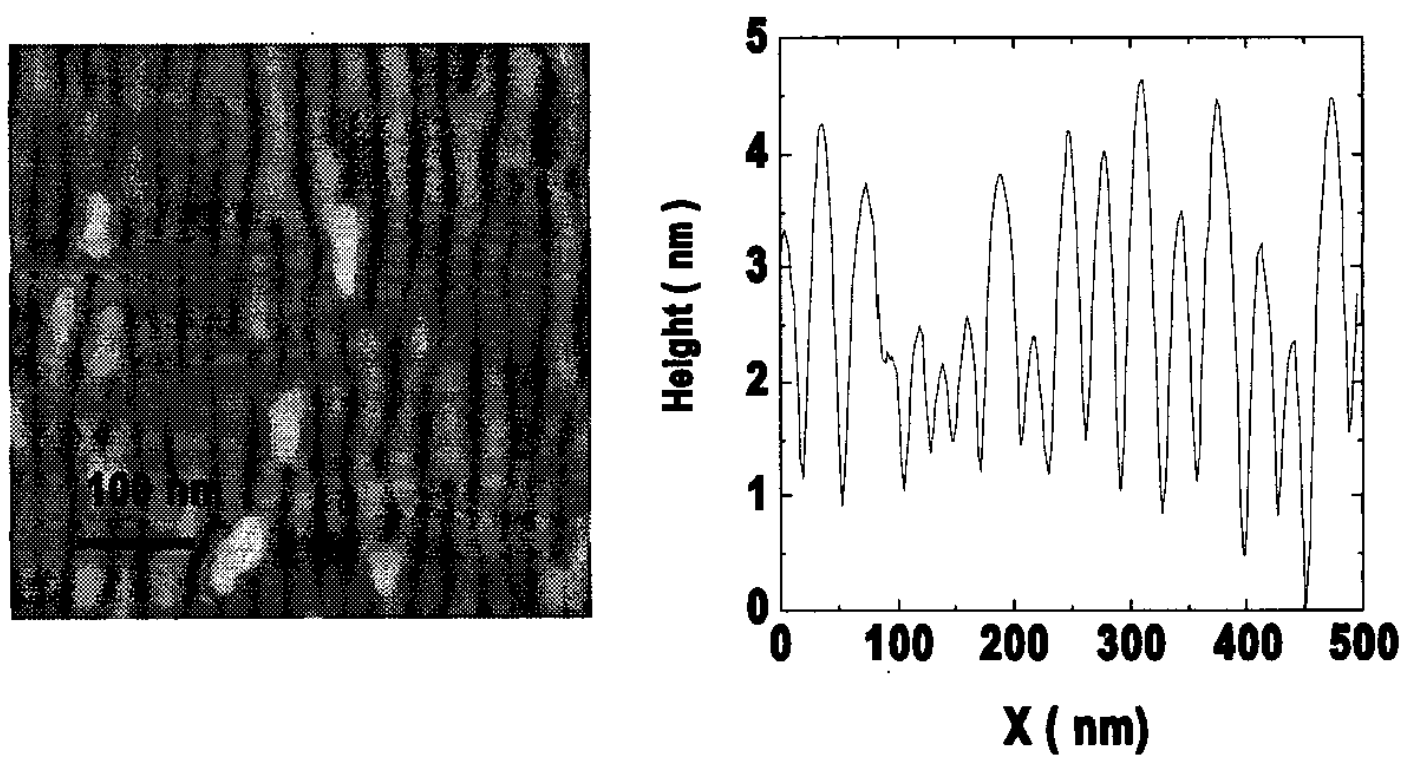

Fig. 2: Atomic Force Microscopy (AFM) view of nanowires formed along [110] by growth of 5.9 monolayers of $\mathrm{In}_{0.90} \mathrm{Ga}_{0.10}$ As on $\operatorname{InP}(001)$. Profile along [110] shows a wire pitch period of $30 \mathrm{~nm}$ and average height $\approx 3.5 \mathrm{~nm}$. 